\title{
Spinal epidural Rosai-Dorfman disease preceding by relapsing uveitis: a case report with literature review
}

\author{
Y-C Huang ${ }^{1,2}$, H-Y Tan ${ }^{3}$, S-M Jung ${ }^{4}$, W-Y Chuang ${ }^{4}$, C-C Chuang ${ }^{1}$, P-W Hsu ${ }^{1}$ and C-N Chang*,1 \\ ${ }^{1}$ Department of Neurosurgery, Chang Gung Memorial Hospital, Chang Gung University, College of Medicine, Taoyuan, \\ Taiwan; ${ }^{2}$ Graduate Institute of Clinical Medical Science, Chang Gung University, Taoyuan, Taiwan; ${ }^{3}$ Department of \\ Ophthalmology, Chang Gung Memorial Hospital, Chang Gung University, College of Medicine, Taoyuan, Taiwan; \\ ${ }^{4}$ Department of Pathology, Chang Gung Memorial Hospital, Chang Gung University, College of Medicine, Taoyuan, \\ Taiwan
}

\begin{abstract}
Study design: Case report.
Setting: Tertiary referral center hospital in Taiwan.

Objectives: To report a case of spinal Rosai-Dorfman disease (RDD) presenting with paraparesis and also preceding by relapsing uveitis for 6 months. A thoracic laminectomy was performed to remove the solid mass. The pathological diagnosis reveals infiltrating histiocytes, emperipolesis and positivity for S-100. There is no recurrence 1 year later with MR imaging. Conclusions: The relapsing idiopathic uveitis may be a prodrome for this unusual disease, because RDD is associated closely to defective immunogical response. Early and accurate diagnosis of CNS RDD may reverse the neurologic deficits by early decompression.

Spinal Cord (2007) 45, 641-644; doi:10.1038/sj.sc.3102006; published online 16 January 2007
\end{abstract}

Keywords: Rosai-Dorfman disease; sinus histiocytosis; spinal neoplasm; uveitis

\section{Introduction}

Rosai-Dorfman disease (RDD) is a rare disorder characterized by an abnormal proliferation of histiocytes. ${ }^{1}$ The most frequent site is cervical lymph node appearing as a painless mass. Other symptoms include fever, leukocytosis, polyclonal hypergammaglobinemia and an elevated erythrocyte sedimentation rate. Only 14 cases of spinal RDD are reported. Ocular involvement is also very rare, especially presenting as uveitis.

\section{Case report}

A 31-year-old female was diagnosed with relapsing uveitis 6 months due to impaired vision acuity (Figure 1). She also had mid-thoracic back pain for 3 months, slow progression of both legs weakness, numbness below umbilicus and mild difficulty in urination. She was sent to the emergency room due to progressive weakness of the legs. There was no fever, palpable lymph nodes and skin lesions. Clinical examinations revealed paresthesia below T10 level. The muscle power of lower limbs is grade 3/5. Magnetic resonance imaging showed a homogeneous enhanced mass lesion at the epidural

*Correspondence: C-N Chang, Department of Neurosurgery, Chang Gung Memorial Hospital, No 5, Fu-shin St, Kweishan, Taoyuan, Taiwan 333, Taiwan space (T6-8), compressing the thecal sac and spinal cord (Figure 2). Viral serology expressed IgG $(+)$ and IgM (-) for toxoplasma, cytomegalovirus and Epstein-Barr virus. For Varicella-Zoster virus, the $\operatorname{IgG}$ is negative, but positive for IgM. The anti-nuclear antigen, rheumatic factor, FTA-ABS and RPR for syphilis and HIV is negative.

An urgent laminectomy of T6-8 was performed to remove a grayish, solid, firm mass over epidural space and the tumor was excised with intact dura. Histologically, the mass revealed chronic inflammation with fibrovascular tissue; in addition, clusters of large eosinophilic histiocytes and interspersed lymphocytes, plasma cells. Emperipolesis with multiple lymphocytes engulfed within histiocytic cells was displayed in some histiocytes. Histiocytes expressed S-100 protein (Figure 3). Thus, the diagnosis of RDD is confirmed.

Postoperatively, the patient walks without assistance soon. However, her vision had decreased from 20/40 OD and 20/100 OS to 20/500 OU at last follow-up due to the sequelae of chronic macular edema following relapsing uveitis despite of topical and systemic corticosteroid treatment. After 1 year, a follow-up MRI shows no concurrent brain or orbital lesion and no recurrence of spinal lesion. 


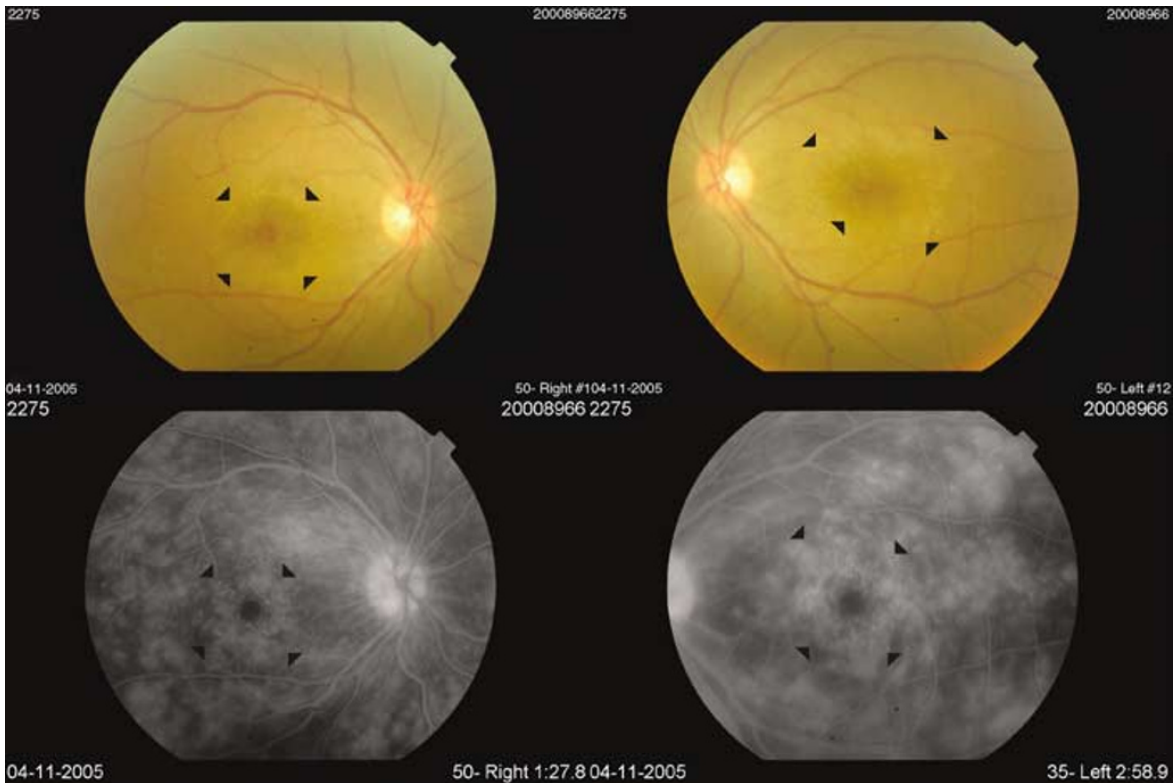

Figure 1 A 31-year-old female with RDD presenting as bilateral relapsing uveitis. Consequent bilateral cystoid macular edema can be demonstrated by the fundus photographs and fluorescence angiogram

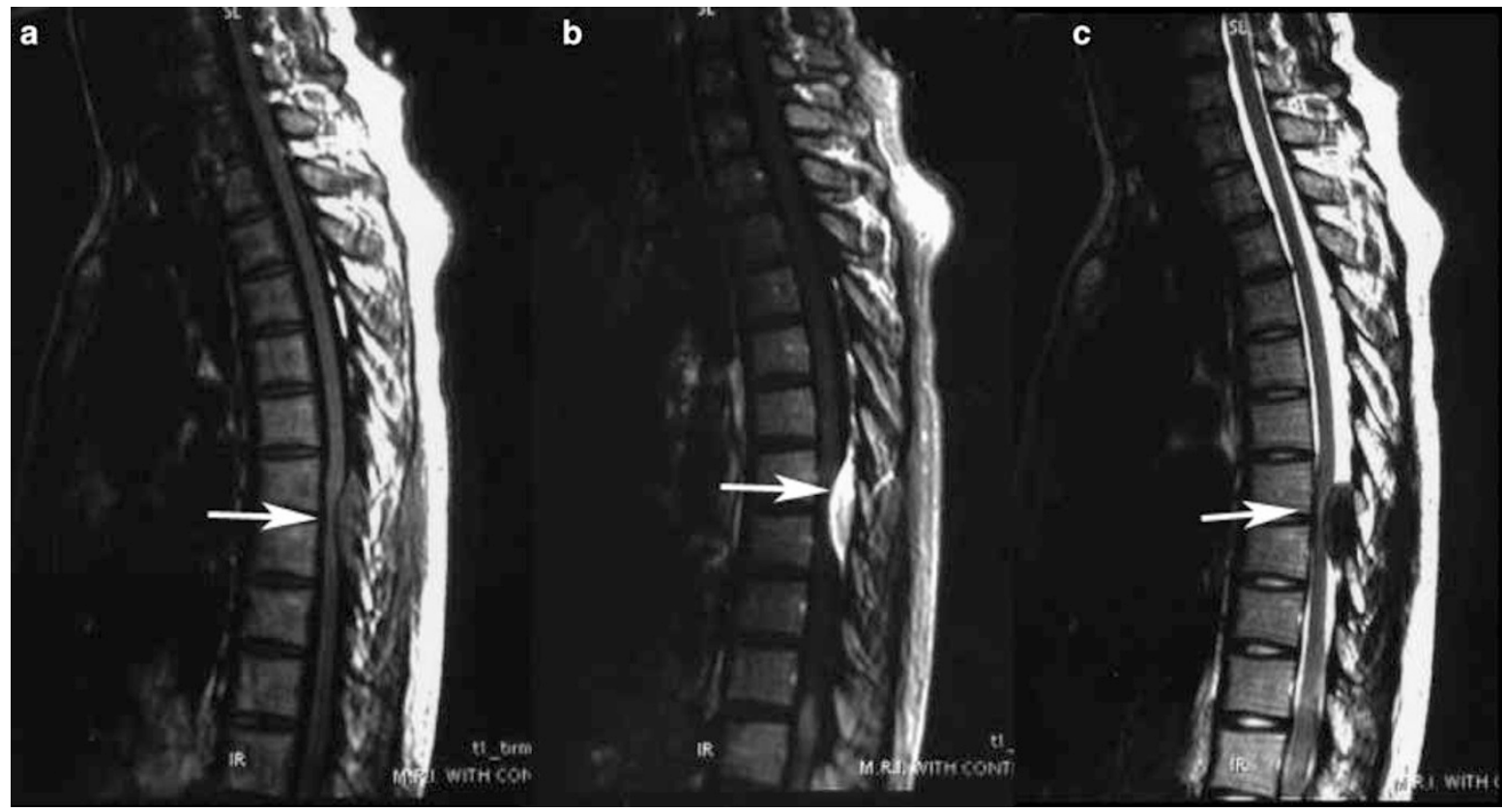

Figure 2 Sagittal MR image revealing a well-circumscribed epidural lesion (arrows), extending from T6 to T8. (a) T1-weighted without enhancement; (b) T1-weighted with enhancement demonstrating a high signal lesion. (c) T2-weighted image

\section{Discussion}

Rosai and Dorfman ${ }^{1}$ first defined sinus histiocytosis with massive lymphadenopathy in 1969. The distinctive histopathologic character is infiltrative of lymphoplasmacytic cells and histiocytes. Reviewing a registry of 423 patients, average prevalence age was 20.6 years with most frequent presentation as cervical lymphadeno- pathy accompanied by fever, general malaise. ${ }^{2}$ Abnormal laboratory findings include anemia (50\%), polyclonal hypergammaglobulinemia $(75 \%)$ and elevating $\operatorname{ESR}(88.5 \%)$. $^{3}$

The most common extranodal sites are the skin, orbit and eyelid, head and neck region, trachea in about $43 \%$ of cases. ${ }^{2}$ CNS RDD is relatively infrequent $(5 \%, 44$ cases). Regions in the brain include dura, venous sinus, 


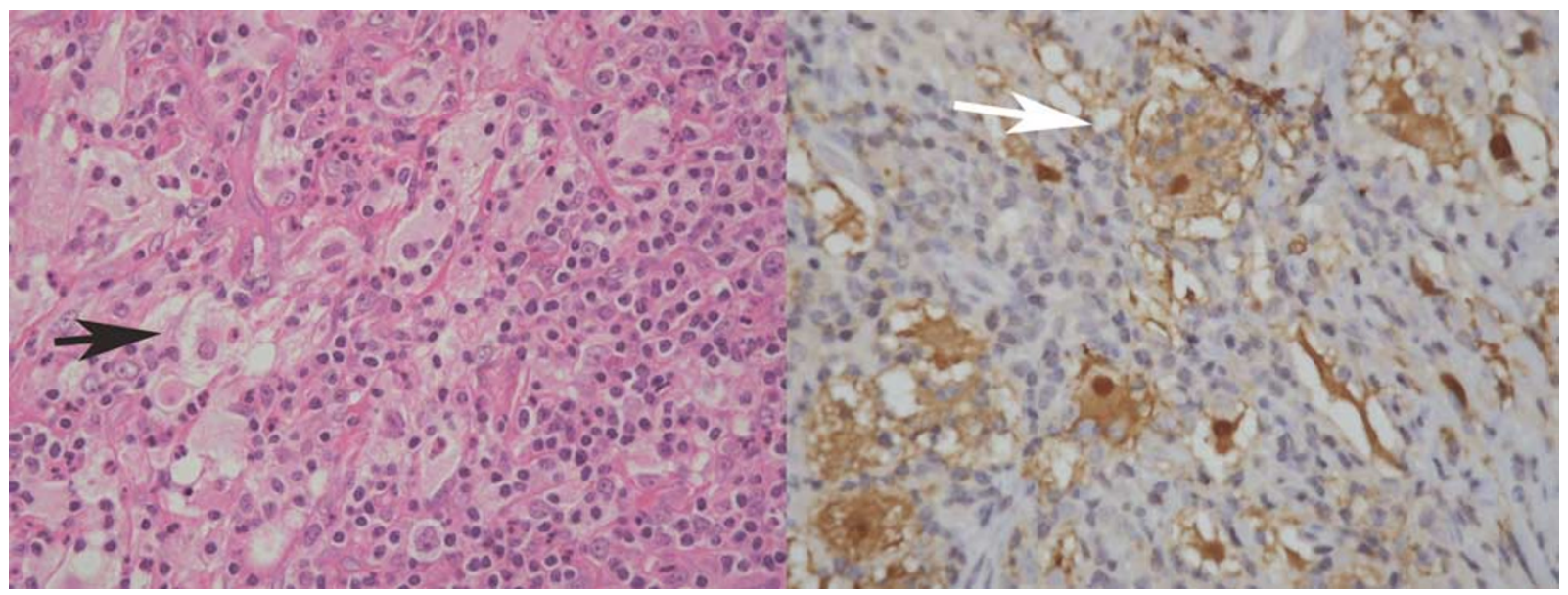

Figure 3 Intermediate-power view of a tissue sample showing numerous, large, pale-staining histiocytes with abundant cytoplasm (black arrow). The background was interspersed with many plasma cells and lymphocyte. Emperiopolesis is evident in H\&E stain $(\times 200)$. High-power field of the same histiocyte demonstrated a histiocytic cell (white arrow) with emperiopolesis and immunopositive for $\mathrm{S}-100$ protein $(\times 400)$

Table 1 Summary of 14 reported spinal RDD cases

\begin{tabular}{|c|c|c|c|}
\hline Location & Location descriptions & Manifestations & Authors/year \\
\hline Subdural extramedullary & Cervical & Quadriparesis & $\begin{array}{l}\text { Arun Bhandari et al } \\
(2006)^{11}\end{array}$ \\
\hline Epidural & $\begin{array}{l}\text { T9 lytic vertebral lesion multiple } \\
\text { bone lesions }\end{array}$ & Papaparesis & Al-Saad et al $(2005)^{12}$ \\
\hline Epidural & T5-9 level & Paraplegia & Hargett et al $(2005)^{13}$ \\
\hline Intramedullary & - & Paraplegia & Tubbs et al $(2005)^{14}$ \\
\hline Intramedullary & - & Sensory disturbance & Sato et al $(2003)^{15}$ \\
\hline Epidural & Dura-based mass & Paraplegia & Andriko et al $(2001)^{4}$ \\
\hline Epidural & Cervical, thoracic and lumbar & $\begin{array}{l}\text { Pain, parasthesia and } \\
\text { weakness of legs }\end{array}$ & Hollowell et al $(2000)^{16}$ \\
\hline Intramedullary & - & Paraplegia & Osenbach et al (1996) ${ }^{17}$ \\
\hline Subdural & $\begin{array}{l}\text { (1) Cervical spine intradural mass } \\
\text { (2) Posterior fossa mass }\end{array}$ & - & Katz et al $(1993)^{7}$ \\
\hline Epidural & Sacrum lesion & - & Unni et al $(1988)^{18}$ \\
\hline Subdural & $\begin{array}{l}\text { Three lobulated subdural masses, } \\
\text { C5-7 }\end{array}$ & $\begin{array}{l}\text { Progressive quadriparesis, } \\
\text { torticollis }\end{array}$ & Chan et al $(1985)^{19}$ \\
\hline Epidural & $\begin{array}{l}\text { (1) Epidural mass, T5-9 } \\
\text { (2) Epidural mass, L5-S1 }\end{array}$ & Paraparesis & Foucar et al $(1982)^{2}$ \\
\hline Epidural & T9 lytic lesion & $\begin{array}{l}\text { Paresthesias of lower } \\
\text { extremities }\end{array}$ & Hass et al $(1978)^{20}$ \\
\hline Epidural & C7-T3 level & Spastic paraparesis & Kessler et al $(1976)^{21}$ \\
\hline
\end{tabular}

intraparenchymal, intraventricle area. ${ }^{4}$ There were 36 cases reported RDD involving eyes were highly accompanied with nasal sinuses involvement. ${ }^{2}$ The common ocular manifestations were soft tissue of the orbit and eyelids. Only seven patients with uveitis were reported. ${ }^{5}$ In addition, 14 cases of spinal RDD were reported (Table 1).

The pathologic findings of RDD are involvement of sinuses with lymphocytes and histiocytes in a background of increased collagen and/or reticulin fiber. The characteristic histiocytic cell has abundant cytoplasm, a pale irregular nucleus and small vesicular nuclei. Emperipolesis consisting of multiple lymphocytes engulfed within histiocytes, which are also seen in Bcell lymphoma, autoimmune hemolytic anemia and myelosclerosis is pathognomonic for RDD. Extranodal RDD, including central nervous system, has been noted to have fewer typical histiocytes and less evidence of emperipolesis. ${ }^{6,7}$ The histiocytes in this case are positive for the dendritic cell-associated protein, S- 100 .

Rosai and Dorfman suggested that RDD is caused by an abnormal immunologic response or infectious factor. Becroft et $a l^{8}$ demonstrated the importance between cellular immunity defect and histiocytic reaction. EBV and HSV 6 were implied to be causative agents or opportunistic infections for patients to develop RDD. In 
our patient, positive IgM response for varicella Zoster, positive IgG for toxoplasma and EBV also implies the immune compromised status.

MRI of RDD shows characteristic low T1 and T2 signals with homogenous contrast enhancement. ${ }^{9}$ Spinal RDD is slow growing without malignant changes. The preservation for neurologic function is thus mandatory. Surgery, radiation therapy, and chemotherapy are treatment strategies. Surgical excision is indicated for spinal cord compression in this case. Andriko et al reported 11 cases of CNS RDD without any adjuvant steroid, chemotherapy or radiation therapy. In our case, the epidural mass is removed without recurrence on a MRI follow-up 1 year later.

Regarding the relapsing uveitis, the prognosis seems to be poor. Topical and systemic corticosteroids were the choice of treatment within all these few case reports, following the treatment modality for idiopathic uveitis. However, the prognosis may be poor due to recurrence, as in our cases. ${ }^{10}$ No other treatment modality has been proposed due to rarity of this presentation. To the best of our knowledge, this case is the first case reported with uveitis and spinal RDD.

\section{Conclusion}

We reported a patient with thoracic spinal epidural RDD preceding by relapsing uveitis. Either spinal epidural RDD or ocular relapsing uveitis is extremely rare. Prompt treatment for spinal RDD is surgical excision. Further investigations toward immunological reactions are important due to its multiple manifestations.

\section{References}

1 Rosai J, Dorfman RF. Sinus histiocytosis with massive lymphadenopathy. A newly recognized benign clinicopathological entity. Arch Pathol 1969; 87: 63-70.

2 Foucar E, Rosai J, Dorfman R. Sinus histiocytosis with massive lymphadenopathy (Rosai-Dorfman disease): review of the entity. Semin Diagn Pathol 1990; 7: 19-73.

3 Jones MP, Rueda-Pedraza ME. Extranodal sinus histiocytosis with massive lymphadenopathy presenting as an intramedullary spinal cord tumor: a case report. $\mathrm{Am} \mathrm{J}$ Hematol 1997; 54: 253-257.

4 Andriko JA, Morrison A, Colegial CH, Davis BJ, Jones RV. Rosai-Dorfman disease isolated to the central nervous system: a report of 11 cases. Mod Pathol 2001; 14: 172-178.

5 Tan HY, Kao LY. Rosai-Dorfman disease manifesting as relapsing uveitis and subconjunctival masses. Chang Gung Med J 2002; 25: 621-625.
6 Shaver EG, Rebsamen SL, Yachnis AT, Sutton LN. Isolated extranodal intracranial sinus histiocytosis in a 5-year-old boy. Case report. J Neurosurg 1993; 79: 769-773.

7 Katz DS, Poe LB, Corona Jr RJ. Sinus histiocytosis with massive lymphadenopathy: a case of simultaneous upper respiratory tract and CNS disease without lymphadenopathy. Am J Neuroradiol 1993; 14: 219-222.

8 Becroft DM, Dix MR, Gillman JC, MacGregor BJ, Shaw RL. Benign sinus histiocytosis with massive lymphadenopathy: transient immunological defects in a child with mediastinal involvement. J Clin Pathol 1973; 26: 463-469.

9 Toh CH et al. Rosai-Dorfman disease with dural sinus invasion. Report of two cases. J Neurosurg 2005; 102: $550-554$.

10 Salim A, Williamson M, Barker F, Hughes J. Steroid responsive cutaneous Rosai-Dorfman disease associated with uveitis and hypothyroidism. Clin Exp Dermatol 2002; 27: 277-279.

11 Bhandari A, Patel PR, Patel MP. Extranodal RosaiDorfman disease with multiple spinal lesions: a rare presentation. Surg Neurol 2006; 65: 308-311.

12 Al-Saad K et al. Extranodal Rosai-Dorfman disease with multifocal bone and epidural involvement causing recurrent spinal cord compression. Pediatr Dev Pathol 2005; 8: 593-598.

13 Hargett C, Bassett T. Atypical presentation of sinus histiocytosis with massive lymphadenopathy as an epidural spinal cord tumor: a case presentation and literature review. J Spinal Disord Tech 2005; 18: 193-196.

14 Tubbs RS et al. Spinal cord compression as a result of Rosai-Dorfman disease of the upper cervical spine in a child. Childs Nerv Syst 2005; 21: 951-954.

15 Sato A et al. Rosai-Dorfman disease presenting with multiple intracranial and intraspinal masses: a case report. No Shinkei Geka 2003; 31: 1199-1204.

16 Hollowell JP, Wolfla CE, Shah NC, Mark LP, Whittaker MH. Rosai-Dorman disease causing cervical myelopathy. Spine 2000; 25: 1453-1456.

17 Osenbach RK. Isolated extranodal sinus histiocytosis presenting as an intramedullary spinal cord tumor with paraplegia. Case report. J Neurosurg 1996; 85: 692-696.

18 Unni KK. Case report 457. Sinus histiocytosis with massive lymphadenopathy (Rosai-Dorfman disease) presenting as lesion in the sacrum. Skeletal Radiol 1988; 17: 129-132.

19 Chan KW, Chow YY, Ghadially FN, Stansfeld AG, Woo $\mathrm{CH}$. Rosai-Dorfman disease presenting as spinal tumor. A case report with ultrastructural and immunohistochemical studies. J Bone Joint Surg Am 1985; 67: 1427-1431.

20 Haas RJ, Helmig MS, Prechtel K. Sinus histiocytosis with massive lymphadenopathy and paraparesis: remission with chemotherapy. A case report. Cancer 1978; 42: 77-80.

21 Kessler E, Srulijes C, Toledo E, Shalit M. Sinus histiocytosis with massive lymphadenopathy and spinal epidural involvement: a case report and review of the literature. Cancer 1976; 38: 1614-1618. 